Portland State University

PDXScholar

\title{
Abusive Supervision in the Workplace: An Examination of Current Research and a Proposal for Preventive Measures
}

Samantha Kemper

Portland State University

Follow this and additional works at: https://pdxscholar.library.pdx.edu/honorstheses

Let us know how access to this document benefits you.

\section{Recommended Citation}

Kemper, Samantha, "Abusive Supervision in the Workplace: An Examination of Current Research and a Proposal for Preventive Measures" (2016). University Honors Theses. Paper 303.

https://doi.org/10.15760/honors.248

This Thesis is brought to you for free and open access. It has been accepted for inclusion in University Honors Theses by an authorized administrator of PDXScholar. Please contact us if we can make this document more accessible: pdxscholar@pdx.edu. 
Running Head: ABUSIVE SUPERVISION

Abusive Supervision in the Workplace: An Examination of Current Research and a Proposal for Preventive Measures

by

Samantha Kemper

An undergraduate honors thesis submitted in partial fulfillment of the

requirements for the degree of

Bachelor of Arts

in

University Honors

and

Business Administration: Management \& Leadership and Human Resource Management

and

Psychology

Thesis Adviser

David E. Caughlin

Portland State University 


\begin{abstract}
Abusive supervision is a serious and growing problem plaguing today's organizations, affecting up to 16 percent of employees. This paper provides an overview of workplace mistreatment research, focusing specifically on abusive supervision and its antecedents and consequences, and proposes a course of action for organizations interested in reducing and preventing abusive supervision. In total, 93 articles were included based on the originality of their contributions to the literature. The central objective of this paper is to create a foundation of knowledge and understanding of abusive supervision, which organizations can then use to identify and prevent the occurrence of abusive supervision. Future research on abusive supervision should focus on creating prevention programs and testing their effectiveness on organizations.
\end{abstract}

Keywords: workplace mistreatment, abusive supervision, destructive leadership, prevention 
Abusive supervision in the workplace:

An examination of current research and a proposal for preventive measures

Workplace mistreatment is comprised of a multitude of behaviors such as violence, aggression, bullying, incivility, and abusive supervision, and it poses a serious problem to organizations. In fact, it has been estimated that physical violence occurs in $20 \%$ of workplaces (Romano, 1994). Further, approximately $41 \%$ of U.S. workers report experiencing nonphysical forms of aggression each year (Schat, Frone, \& Kelloway, 2006). While mistreatment can be perpetrated by different sources, recent meta-analytic evidence suggests the outcomes of workplace mistreatment are more consequential for victims when perpetrated by a supervisor as opposed to a coworker or organizational outsider (e.g., client, patient, customer) (Hershcovis \& Barling, 2010). For instance, Hershcovis and Barling's (2010) meta-analytic investigation showed that mistreatment perpetrated by a supervisor corresponded to a systematically stronger relationship with the following victim outcomes: job dissatisfaction, psychological distress, job performance, and turnover intentions. With respect to its effects on thoughts to quit the organization, the associated increased likelihood of actual turnover behavior can be costly to the organization. According to one estimate, costs of turnover can constitute as much as $5 \%$ of an organization's operating budget (Hinkin \& Tracey, 2000). As such, a preponderance of evidence points to the ill effects of workplace mistreatment.

A specific form of workplace mistreatment, abusive supervision, represents a serious and growing problem plaguing today's organizations due to its negative consequences for subordinates, supervisors, and the work environment. Research shows that between $10-16 \%$ of American workers experience abusive supervision on a regular basis (Tepper, Duffy, Hoobler, \& Ensley, 2004). Abusive supervision can result in annual organizational costs of approximately \$23.8 billion (Tepper, Duffy, Henle, \& Lambert, 2006). As such, additional research is needed to 
understand abusive supervision and its antecedents so as to prevent and reduce occurrences of this problematic form of workplace mistreatment.

To date, a large amount of research has been conducted in relation to abusive supervision over the past fifteen years. It has been published in a number of journals, including the Academy of Management Journal, Leadership Quarterly, Journal of Business and Psychology, Human Resource Management Journal, Personnel Psychology, Journal of Organizational Behavior, Journal of Applied Psychology, Journal of Business Ethics, and Journal of Occupational Health Psychology. Research has been published in different discourse communities, showing that abusive supervision is not only of interest in the world of business but also in the field of applied psychology. While the construct may be defined in different ways, there is general agreement that abusive supervision ${ }^{1}$ is defined as "the sustained display of hostile verbal and nonverbal behaviors, excluding physical contact" (Tepper, 2000, p. 178). Further, in the management and industrial/organizational psychology literatures, abusive supervision represents the confluence of two distinct research areas: destructive leadership and workplace mistreatment. With respect to destructive leadership, research on leadership has traditionally focused on positive or constructive forms leadership behaviors.

Recently, there has been a notable increase in the amount of destructive leadership in the workplace, although specific causes of this increase are still unclear (Harvey, Stoner, Hochwarter, \& Kacmar, 2007). This has prompted an increased interest in destructive leadership behavior, in general. Over the past decade, the amount of research on destructive leadership behavior - and specifically on abusive supervision - has increased dramatically (Martinko, Harvey, Brees, \& Mackey, 2013). Nevertheless, the problem still exists, and while there have

\footnotetext{
${ }^{1}$ For a complete list of key terms, refer to Appendix A.
} 
been attempts at investigating coping methods, there is a dearth of information available regarding methods for preventing abusive supervision and other forms of destructive leadership.

In contrast, there is growing evidence that documents the negative consequences of abusive supervision in the workplace, particularly with respect to costs for both organizations and their employees. For example, abusive supervision may result in higher turnover, lower performance, and lower job satisfaction (Tepper, 2000). To date, most research has focused on coping with the psychological aftermath of abusive supervision instead of preventing it before it happens - that is, a reactive and not a preventive strategy (Tepper, 2007). Subordinates who experience abusive supervision rarely report it due to the fact that their continued employment and any advancement opportunities often lies in the hands of their supervisor (Xu, Loi, \& Lam, 2015). Instead, they adopt avoidant or passive coping strategies in order to distance themselves from the source of the stress (Xu et al., 2015). By coping silently or bringing up the problem in an exit interview with an organization, employees do not give organizations the chance to address and mediate the problem. As such, adopting a primary prevention approach (Quick, 1999), in which the stressor of abusive supervision is eliminated before it occurs, represents a desirable alternative addressing abusive supervision - an approach that stands in contrast to reacting to and treating the symptoms of exposure to abusive supervision.

Regarding a preventive stance toward abusive supervision, researchers have suggested that organizations are responsible for finding ways to address or prevent abusive supervision (Tepper et al., 2006); however, to date, I have not been able to identify any proposed or tested abusive supervision-specific prevention programs. Because the primary responsibility for addressing and preventing abusive supervision lies in the hands of the organization (Tepper, Duffy, Henle, \& Lambert, 2006), it is my contention that organizations should implement some 
form of training or development program that focuses on modeling the appropriate workplace behavior while discouraging inappropriate behavior like abusive supervision. Such programs have been introduced and evaluated for other forms of workplace mistreatment such as incivility (viz., Civility, Respect, and Engagement at Work [CREW] intervention; Leiter, Laschinger, Day, \& Oore, 2011); yet, based on my search of the extant literature, no such programs exist specifically for abusive supervision.

As a prerequisite to developing a preventive intervention program, it is imperative that organizations understand abusive supervision in depth - both in respect to its consequences and antecedents - in order to recognize and address such destructive behavior before it becomes a costly organizational problem. Moreover, many would argue that organizations have a moral obligation to ensure the health and safety of its employees. In direct service to these objectives, this paper will investigate how organizations can use existing knowledge of abusive supervision to identify and prevent its occurrence in the workplace before it becomes a problem. Further, this paper will address the current state of research on abusive supervision and identify any gaps in the literature. In sum, my overarching goal is to review the extant research related to abusive supervision in order to inform potential ways to respond to and ideally prevent abusive supervision.

\section{Methodology}

To gather the information necessary to achieve the goals of this paper, I conducted a literature search for prior studies on abusive supervision using a computer-based search of electronic databases, a manual search of selected journals, and a manual search of the reference lists of articles. I searched for articles and studies published between the years 1985 and 2015 on databases such as PsycINFO, GoogleScholar, and other ProQuest databases. My search terms 
included abusive supervision, destructive leadership, workplace bullying, workplace aggression, and workplace violence. Using abusive supervision as the only search terms on PsycINFO with a date range of 1985-2015 I yielded 208 results, and out of these 208 approximately one-third of them were accessible in free PDF format. I also manually searched journal publications in the Journal of Applied Psychology, Journal of Occupational Health Psychology, Journal of Management, Personnel Psychology, The Leadership Quarterly, and within Elsevier Science Journals. This journal publication and database search was conducted during a two-week time period, and 44 articles were retained. Keywords that were required to be in present in these articles include abusive supervision, destructive leadership behavior, workplace aggression, or workplace bullying. I then searched the reference lists of those 44 articles for additional relevant articles.

In total, 93 articles were included in this paper. My decision to retain and use these 93 articles was based on their respective originality and/or seminal nature, and with respect to literature reviews or syntheses, their comprehensiveness. Articles were required to relate to abusive supervision in an organizational context where the supervisor and the subordinate are both adults, as opposed to a situation where abusive supervision is being inflicted upon children. However, the retained articles were heterogeneous in terms of sample size, location of the study, sample size, demographic of participants, jobs held by participants (i.e. blue collar, white collar, military), and the duration and design of the study. Articles that contributed new findings to the literature regarding the relationship between abusive supervision and another variable (e.g., work withdrawal; Chi \& Liang, 2013; workplace deviance; Mitchell \& Ambrose, 2007; work-family conflict; Carlson, Ferguson, Hunter, \& Whitten, 2012) were retained. Subsequent literature searches were conducted over a longer period of time, using the references listed by the authors 
in the first 44 articles, and provided a much more comprehensive and well-rounded body of literature. The relevant information found in these 93 articles is summarized in the literature review in the following section.

\section{Literature Review}

Based on my search of the literature, I organize the subsequent literature review as follows. First, I begin with a description of the shifting interest from successful to unsuccessful (or constructive to destructive, or positive to negative) leadership. Second, I provide general overviews of workplace mistreatment and destructive leadership. Third and finally, I review the nomological network of abusive supervision. The review is intended to take the reader from a more general overview of this issue of destructive leadership and workplace mistreatment to a specific focus on abusive supervision that will then be maintained through the rest of this paper. Research findings on the negative effects of abusive supervision will be discussed, and gaps in the current literature will be addressed. This literature review ties in with the original overarching objective of this thesis paper, which is to use the knowledge and research available on abusive supervision to identify and prevent its occurrence in the workplace.

To date, the preponderance of leadership research has focused on the outcomes of either positive or negative leadership behaviors - namely, transformational leadership and abusive supervision, respectively. Research on the predictors of leadership has lagged behind in the area of negative leadership areas, and one potential antecedent of abusive supervision that has been neglected is the leader's own psychological well-being (Byrne, Dionisi, Barling, Akers, Robertson, Lys, \& Dupré, 2014). Up this point in time, the research that has been conducted up has focused primarily on the consequences of abusive supervision. In many cases, this has also been limited to the investigation of negative effects experienced by the victim or target. The 
definition explicitly states that it is the subordinate's perception of the abuse, which in turn confines our knowledge of abusive supervision to only one perspective. There has, however, been a tremendous amount of insight gained on how abusive supervision can negatively impact an organization, but there are still gaps in the current literature that need to be filled. With regard to research methodology and design, studies have employed varying sample sizes but most have had fewer than 400 participants, so it is difficult to say how well this research generalizes to broader working populations. To date, the literature has focused extensively on subordinates but has yet to adequately investigate the effects of abusive supervision has on the supervisors themselves (i.e., the perpetrators), as well as the characteristics of the supervisor that make the individual more likely to engage in such destructive behaviors.

\section{Leadership - From Constructive to Destructive}

The majority of research on workplace leadership has investigated the constructive, effective, and successful forms of leadership behaviors as opposed to the destructive forms of leadership behaviors (Kelloway, Mullen, \& Francis, 2006). Such forms of positive leadership behaviors include transformational leadership, authentic leadership, and servant leadership. Historically, there was an implicit assumption that ineffective leadership was simply the absence of leadership - sometimes called laissez-faire leadership (Ashforth, 1994). More recent research, however, has provided evidence that this is likely not the case (Kelloway et al., 2006). For example, some leaders exhibit destructive qualities or behaviors but are not necessarily ineffective leaders when it comes to encouraging the task-related behaviors of followers. As such, leadership behaviors do not exist on a single dimension; rather, leadership behaviors likely constitute a complex, multidimensional superordinate construct comprised of subordinate 
dimensions - such as transformational leadership and destructive leadership - that are not necessarily mutually exclusive.

By looking more closely at this dark side of leadership, organizations can develop a more accurate view of leadership as a broader concept. This could contribute to the general understanding of leadership effectiveness and leadership development (Einarsen, Aasland, \& Skogstad, 2007). Finally, understanding and preventing destructive leadership may be just as important as understanding and enhancing the positive aspects of leadership because the overall health of an organization, like an organism, depends on isolating and removing toxic components.

\section{The Intersection of Leadership and Mistreatment}

In the following section, I expound upon the interaction of leadership and mistreatment in organizations to better understand the dark side of leadership. Specifically, I address the role of mistreatment in the related concepts of destructive leadership and abusive supervision. In the following paragraphs, I provide an overview of workplace mistreatment as it relates to destructive leadership and abusive supervision. 


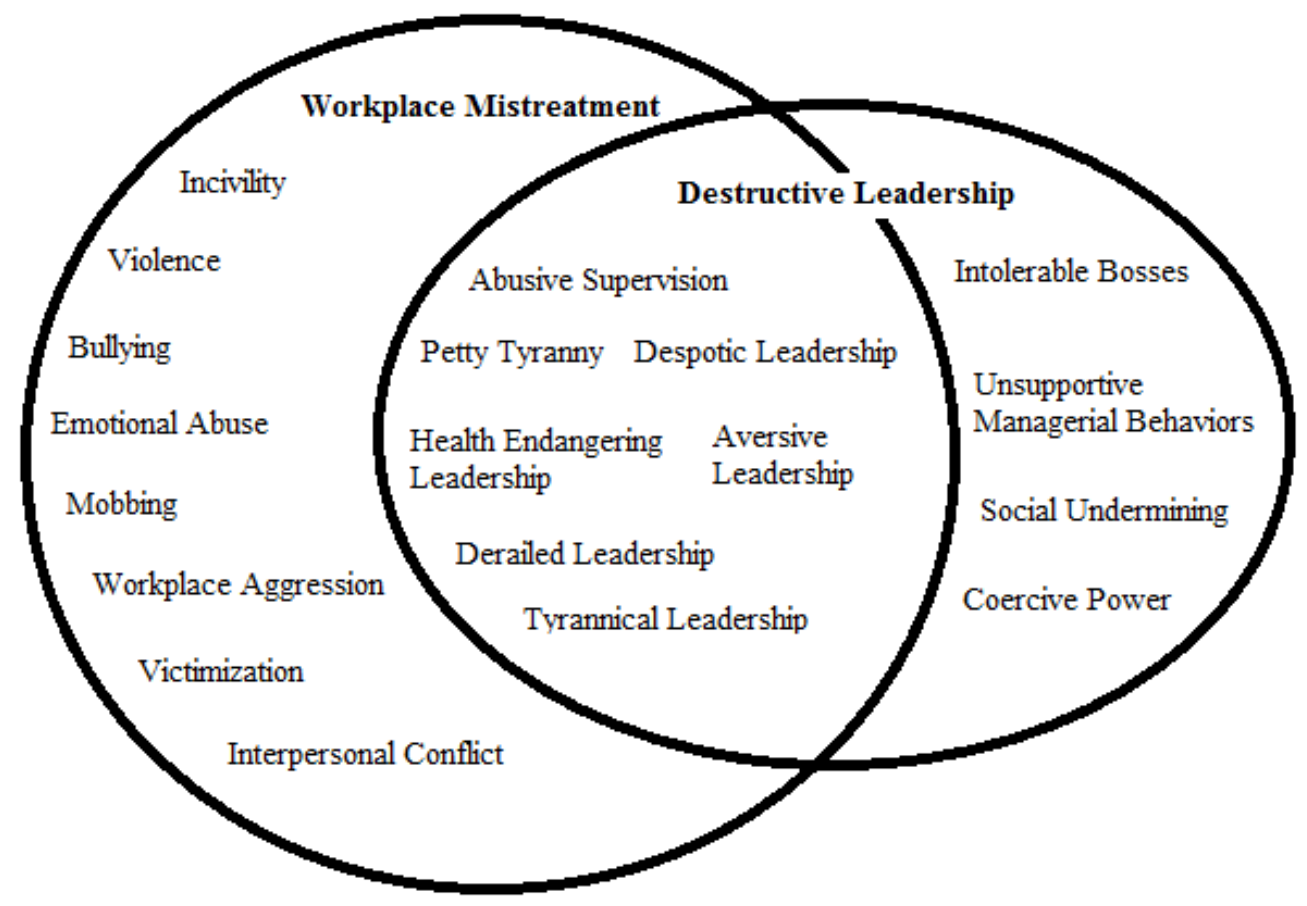

Figure 1. Workplace Mistreatment Constructs

As shown in Figure 1 above, workplace mistreatment is a broad concept comprised of a variety of constructs. Destructive leadership falls mostly within the domain of workplace mistreatment, but also has its own set of related constructs that may exist outside of the workplace mistreatment domain. Abusive supervision is a form of workplace mistreatment, but is more specifically defined under the category of destructive leadership because it requires the direction of abuse to be from the supervisor to the subordinate.

Workplace mistreatment and abusive supervision. Abusive supervision sits at the intersection of destructive leadership and mistreatment, specifically destructive leadership and bullying. Research on workplace mistreatment has increased dramatically over the last 15 years (Hershcovis, 2011). Workplace mistreatment includes various constructs, including bullying, social undermining, mobbing, workplace aggression, emotional abuse, victimization, interpersonal conflict, and abusive supervision. As a specific form of mistreatment, workplace 
bullying is conceptually similar to abusive supervision in that it involves repeated or sustained acts of mistreatment over time. More formally, workplace bullying is defined as "the process in which an employee is subjected to frequent negative acts for a relatively long period of time by peers or supervisors, against which defense or retaliation is hindered by the recognition of a formal or informal power imbalance" (Glambek, Matthiesen, Hetland, \& Einarsen, 2014, p. 255); in addition, workplace bullying encompasses such specific acts as unfair criticism, providing the target with excessive workloads or work tasks irrelevant to the job, and relocating the target to humiliating and degrading tasks and positions. As suggested in Glambek and colleagues' definition, workplace bullying represents a parent construct to abusive supervision in that the repeated acts of abuse may come from either a peer or a supervisor. That is, abusive supervision can be conceptualized as a specific form of workplace bullying. Accordingly, it is worth reviewing the construct of workplace bullying in greater detail so as to understand more completely the focal construct of abusive supervision.

Workplace bullying may be work or person-related and can involve verbal aggression, obstruction of work tasks, physical violence, social exclusion and veiled job sabotage (Glambek et al., 2014). As with any form of workplace mistreatment, there may be a higher number of workplace bullying victims than who actually choose to report or disclose such treatment for fear of retaliation or other such consequences. Employees who are bullied can also experience exclusion from work, which comes in various forms, including department transfers and internal relocation, being discharged, or taking sick leave (Glambek et al., 2014). Further, workplace bullying has been associated with victims' increased intentions to leave the organization (Glambek et al., 2014); for example, targets of workplace bullying may consider quitting as an avenue to escape from the situation when they see no other way to cope with it or resolve it. 
Abusive supervision constitutes a more specific form of workplace bullying in that it involves bullying and other mistreatment behaviors perpetrated specifically by the supervisor. Estimates vary with respect to the proportion of workplace bullying incidents that can be classified as abusive supervision; however, collectively such estimates indicate that a non-trivial proportion of workplace bullying acts constitute abusive supervision. First, in the mid-1990s, a study by UNISON (1997) indicated that $40 \%$ of survey respondents had experienced bullying from a leader during their career (UNISON, 1997). Second, Namie and Namie (2000) later found that $89 \%$ of respondents who reported experiencing bullying at work perceived a leader to be the main bully, thereby contributing additional evidence that leaders do in fact behave in an abusive and destructive manner toward their subordinates. Third and even more recently, Einarsen, Hoel, and Cooper (2003) found that $80 \%$ of workplace bullying cases involve a superior as the alleged bully. Together these findings indicate that a relatively sizable proportion of workplace bullying incidents can be classified more precisely as acts of abusive supervision.

Destructive leadership and abusive supervision. As described above, abusive supervision also constitutes a specific type of destructive leadership. Accordingly, it is also important to understand abusive supervision from the lens of destructive leadership. With regard to the consequences of abusive supervision, prior research has contributed support for the proposition that negative events that occur during social interactions tend to have a stronger effect than positive events (Einarsen et al., 2007). Following the logic of this proposition, one might conclude that preventing abusive supervision may be more important than enhancing the construct forms of supervisor behaviors such as positive or constructive leadership (Einarsen et al., 2007) and general supportive supervision. 
Leaders in organizations have the potential to positively or negatively influence subordinate attitudes, behaviors, and their general well-being with every single workplace interaction (Michel, Newness, \& Duniewicz, 2015). This means that every workplace interaction is critically important. Whether or not that workplace interaction is an example of positive or negative displays of leadership is even more important. A few types of leadership that fall under the category of destructive leadership include abusive supervision (Hornstein, 1996; Tepper, 2000), health-endangering leadership (Kile, 1990), petty tyrant leadership (Ashforth, 1994), bullying (Namie \& Namie, 2000), derailed leadership (Schackleton, 1995), intolerable bosses (Lombardo \& McCall, 1984), psychopathic behavior (Furnham \& Taylor, 2004), and harassing leadership (Brodsky, 1976).

At this point, it is important to reiterate the definition of abusive supervision used for this review. Specifically, abusive supervision refers to a subcategory of destructive leadership, and has been defined by Tepper (2000) as "subordinates' perceptions of the extent to which their supervisors engage in the sustained display of hostile verbal and nonverbal behaviors, excluding physical contact" (p. 178). Abusive supervision has also been defined as representing the prolonged emotional or psychological mistreatment of subordinates (Harvey et al., 2007). Some examples of these behaviors include public ridicule, invasion of privacy, taking undue credit, inappropriately assigning blame, rudeness, breaking promises, inconsiderate actions, the silent treatment, ridiculing subordinates in front of others, withholding important information, and the use of disparaging language, threats, and intimidation tactics. This does not include physical contact, as that would fall under the spectrum of violent behaviors (Harris, Kacmar, \& Zivnuska, 2007). Abusive supervision must also occur more than once, which rules out isolated incidents of these behaviors. There has to be a sustained pattern of abuse on a regular basis over an extended 
period of time (Harvey et al., 2007). Vigoda-Gadot (2007) suggests that the original definition of abusive supervision can be expanded to include exploitative behaviors and excessive requests made by managers that cannot be refused. Compulsory citizenship behaviors fall under this revised definition of abusive supervision and are destructive behaviors that negatively impact organizations. For a list of specific behaviors that are indicative of abusive supervision, please refer to Appendix B to review the 15-item measure of abusive supervision developed by Tepper and colleagues (2000).

As previously mentioned in the introduction, research shows that between 10 and $16 \%$ of American workers experience abusive supervision on a regular basis (Tepper et al., 2004). Once again, these data are based on employees who were willing to report that they were experiencing abusive supervision. The actual percentage might be even higher, depending on how many employees experienced abusive supervision on a regular basis but chose not to report it. Media reports have indicated that the frequency of this abuse has increased in recent years (Harvey et al., 2007); however, there has been no specific cause associated or linked with this increase.

Figure 2 (shown below) depicts some of the antecedents and consequences of abusive supervision, which will be discussed in greater detail in the following sections. 


\section{Antecedents}

- Psychological resource depletion (Byrne et al., 2013)

- Psychological contract violation (Rousseau, 1995)

- Presence of depressive symptoms and anxiety (Byrne et al., 2013)

- Increased workplace alcohol consumption (Byrne et al., 2013)

\section{Abusive Behaviors}

Sustained display of hostile verbal or nonverbal behaviors (Tepper, 2000), including public ridicule, invasion of privacy, taking undue credit, inappropriately assigning blame, rudeness, breaking promises, inconsiderate actions, silent treatment, ridiculing subordinates in front of others, withholding important language, and using disparaging language, threats, and intimidation tactics.

\section{Consequences}

- Lower employee performance (Martinko et al., 2013)

- Higher turnover (Tepper et al., 2006)

- Workplace deviance (Hershcovis \& Barling, 2010)

- Family Conflict (Hoobler \& Brass, 2006)

Figure 2. Abusive supervision as a process

\section{Antecedents of Abusive Supervision}

The growing body of literature on the antecedents of abusive supervision, prompted by a desire to reduce abusive supervision, has significantly enhanced our understanding of why leaders abuse their followers (Yam, Fehr, Keng-Highberger, Klotz, \& Reynolds, 2015). Such research indicates that leaders are more likely to abuse their followers in hostile organizational climates, or when they possess certain traits such as high levels of Machiavellianism (Kiewetz, Restubog, Zagenczyk, Scott, Garcia, \& Tang, 2012) and low levels of emotional intelligence (Xiaqi, Kun, Chongsen, \& Sufang, 2012). Research has also suggested that the impact of abusive supervision is stronger within mechanistic organizational structures (i.e., highly centralized 
structures with predominantly top-down communication) than in organic structures (i.e., less centralized and more collaborative) (Aryee, Sun, Chen, \& Debrah, 2008). Industries such as the military and healthcare appear to be particularly susceptible to abusive behaviors, due to the fact that they are characterized by high work demands, pressure, risk, and high costs associated with failure (Tepper, 2007). These types of organizations might drive members to engage in aggressive behaviors such as abusive supervision (Tepper, 2007). One perspective that has not been examined as closely is leaders' psychological health and well-being, as most research has traditionally focused on subordinates' well-being as a consequence of experiencing abusive supervision (Bamberger \& Bacharach, 2006; Kelloway, Turner, Barling, \& Loughlin, 2012).

It could be argued that the lack of interest in leaders' well-being derives from the assumption that all leaders enjoy a positive state of psychological health (Byrne et al., 2014). Leaders are often focused more on follower well-being and might not always think about their own health because they do not want to appear weak (Byrne et al., 2014). A large number of personal resources are required for enacting high-quality leadership. Leaders must influence specific tasks, goals and broad strategies, employ commitment and compliance, and organizational culture, social relationships, team effectiveness, and decision-making (Finkelstein, Hambrick, \& Cannella, 1996; Hackman, 2002; Parry, 2011; Yukl, 2000).

Abusive supervision may also reflect leadership behaviors that ensue when resources are depleted (Byrne et al., 2014). Conservation of resources (COR) theory (Hobfoll, 2001) has been used to explain the outcomes of negative leadership. COR theory predicts that individuals who lack personal resources will experience stress, and will also be prone to further resource loss. People strive to obtain and protect a number of valued psychological characteristics, objects, energies, and conditions (Diener \& Fujita, 1995; Hobfoll, 1989, 2001). 
Depletion of the leader's psychological well-being, as well as the presence of depressive symptoms, anxiety, and workplace alcohol consumption specifically, have been found to inhibit transformational leadership behaviors and minimize the leader's ability to refrain from the enactment of abusive supervision (Byrne et al., 2014). A leader's resources are central to their ability to control their behavior and emotions, and when these resources are depleted, leaders are left susceptible to counterproductive and damaging interactions with their subordinates (Byrne et al., 2014). Self-control has been shown to be a limited resource that can become depleted, resulting in increased aggressive responses and destructive forms of conflict resolution (Baumeister, Bratslavsky, Muraven, \& Tice, 1998; Finkel \& Campbell, 2001; Hedgcock, Vohs \& Rao, 2012; Stucke \& Baumeister, 2006). Depleted self-control impairs the ability to engage in appropriate social interactions, and the depletion of sleep and executive functioning resources predict aggressive behavior (DeWall, Baumeister, Stillman, \& Gailliot, 2007; Kahn-Greene, Lipizzi, Conrad, Kamimori \& Killgore, 2006; Von Hippel \& Gonsalkorale, 2005) such as abusive supervision.

Abusive supervision can also be caused by a psychological contract violation between a supervisor and their employer. A psychological contract is formed by an employee's beliefs about what they feel they are entitled to in an organization, based on implicit or explicit promises made by the employer (Hoobler \& Brass, 2006). In one study, 79\% of the people who left an organization reported psychological contract violations, yet so did $52 \%$ of the people that stayed (Robinson \& Rousseau, 1994). Psychological contract violations can lead to the employee feeling a sense of loss or psychological injury (Rousseau, 1995). Employees do not always terminate their relationship with an employer directly following a psychological contract violation, and as a result there may be repercussions for employers who have current employees 
living with violated contracts (Hoobler et al., 2006). One of these negative repercussions could be abusive supervision. When an individual's psychological contract is violated, they may decide to retaliate but may be unable to retaliate against their superior without there being negative consequences such as demotions or disciplinary action. They might instead turn their displaced aggression toward their subordinates, whom they have control over. They might feel this behavior is justified and also that it puts them in a position or status of someone who cannot be taken advantage of (Hoobler et al., 2006).

Results of Hoobler and colleagues' (2006) study indicated that when supervisors felt their employer had not lived up to what they expected, their subordinates reported a higher incidence of abusive supervision, suggesting that when things go wrong on the job employees target less powerful others at whose expense they displace their aggression. If supervisors retaliate against their superiors, they could subject themselves to further negative organizational consequences such as demotions or disciplinary action, so they instead turn their displaced aggression toward organizational members over whom they have control - their subordinates (Hampton, 1988). Supervisors may engage in abuse of their subordinates because they feel it is justified (Tedeschi \& Norman, 1985). Even typically nonaggressive individuals may feel justified to react aggressively if they believe they were targeted by a person with aggressive intent (Hoobler et al., 2006).

Mistreatment climate, defined as “employees' individual or shared perceptions of organizational policies, procedures, and practices focused on deterring mistreatment" (Yang, Caughlin, Gaxcia, Truxillo, \& Spector, 2014, p. 2), has also been suggested as an antecedent to abusive supervision. Psychological mistreatment climate refers to unique individual perceptions of attributes associated with workplace mistreatment, while unit-level mistreatment climate 
refers to the shared understandings of these attributes (Yang et al., 2014). Meta-analytic indicates that better psychological mistreatment climate has been associated with less mistreatment exposure, less emotional and physical strain, and better job attitudes (Yang et al., 2014).

Research examining the predictors of supervisor-targeted aggression has only emerged relatively recently (Barling, 1996). Much of this research has demonstrated the importance of employees' interpersonal treatment by their supervisors as a predictor of supervisor-targeted aggression (Folger \& Baron, 1996; Tepper, 2000). Both employees’ work experiences and personal characteristics are related to the likelihood of becoming aggressive toward their supervisors (Inness, Barling \& Turner, 2005). When employees believe they have been treated unfairly, they may be motivated to reestablish a sense of fairness, and one strategy they might use to do this is through aggressive retaliation (Aquino, Tripp \& Bies, 2001; Cropanzano \& Folger, 1989; Folger et al. 1996; Greenberg, 1993), potentially in the form of abusive supervision.

A meta-analysis of the antecedents of abusive supervision was published in 2015 by Zhang and Bednall. 74 studies comprising over 30,063 participants were included in this metaanalysis, examining the relationship between abusive supervision and different antecedent categories (Zhang \& Bednall, 2015). The four categories of abusive antecedents that have been established are supervisor-related antecedents (i.e. negative experiences, negative affect, stress, perceived lack of interactional and procedural justice), organization-related antecedents (i.e. organizational norms and aspects of organizational climate), subordinate-related antecedents (i.e. political skill, stability, cynical attribution, negative affectivity, power distance, supervisordirected attribution, traditionality, narcissism, neuroticism, conscientiousness, extraversion, and agreeableness), and demographic characteristics of both supervisors and subordinates (i.e. age, 
tenure, and time spent with one another) (Zhang et al., 2015). Results of this meta-analysis provide general support for the hypotheses related to each of the four categories of abusive antecedents (Zhang et al., 2015). These results are summarized in the following paragraph.

When examining the relationship between abusive supervision and supervisor-related antecedents, results showed that abusive supervision is positively related to supervisor's negative experiences, negative affect, and stress, and is negatively related to supervisors' perceived interactional and procedural justice (Zhang et al., 2015). Both authoritarian and unethical leadership are positively related to abusive supervision, while all constructive leadership styles (including ethical leadership, supportive leadership, and transformational leadership) are negatively related to abusive supervision (Zhang et al., 2015). Supervisors' emotional intelligence is negatively related to abusive supervision, however, the effects of supervisors' power and Machiavellianism failed to reach significance (Zhang et al., 2015). When testing the relationship between abusive supervision and certain aspects of organizational climate, results showed that abusive supervision is positively related to aggressive norm and negatively related to organizational sanction (Zhang et al., 2015). When examining the relationships between abusive supervision and subordinates' characteristics, results showed that abusive supervision is positively related to subordinates' political skill, cynical attribution, negative affectivity, power distance, and supervisor-directed attribution, while negatively related to subordinates' stability and traditionality (Zhang et al., 2015). For subordinates' personality, narcissism and neuroticism are positively related to abusive supervision, while conscientiousness, agreeableness, and extraversion are negatively related (Zhang et al., 2015). When examining the relationship between abusive supervision and demographic variables, only subordinates' age is significantly related (negatively) to abusive supervision (Zhang et al., 2015). This meta-analytic review is the 
first comprehensive analysis of the antecedents of abusive supervision and provides a framework for future research (Zhang et al., 2015). Previous research has traditionally focused on the consequences of abusive supervision, which are discussed in the following section.

\section{Consequences of Abusive Supervision}

Abusive supervision yields negative effect on subordinates, supervisors, and the organization as a whole. It can be costly at the individual and at the organizational level. Abusive supervision impacts not only those directly involved but also the work environment. Other employees can also be affected by a situation involving an abusive supervisor and a subordinate employee, resulting in a general productivity decline. Further, abusive supervision may in turn negatively impact the family life of victims (Hoobler et al., 2006). It is important to trace the negative effects of abusive supervision back to the individual employee in order to lower the overall organizational costs of this problem. Moreover, it is important to approach abusive supervision from a systems theory perspective (Bronfenbrenner \& Morris, 1998). That is, the consequences of abusive supervision are not constrained to the supervisor-employee dyad; rather, the effects of abusive supervision may potentially influence others in the work domain as well as the home domain, including family members.

Consequences for targets. Empirical research usually examines abuse from the subordinate's (target's or victim's) perspective (Mitchell, Vogel, \& Folger, 2015). This research has looked at everything from the effects of abusive supervision on employee productivity to the effects of abusive supervision on work-family conflict. The argument can be made that research on the negative consequences of abusive supervision has reached a saturation point (Martinko et al., 2013). Abusive supervision has many negative effects on the subordinates, including lower levels of job satisfaction, psychological and mental health issues, physical health issues, work- 
family conflict, increased turnover intentions, high job strain, job burnout, increased blood pressure, decreased organizational commitment, decreased self-efficacy, increased workplace deviance, increased aggressive behaviors, and lower overall performance (Martinko et al., 2013). Individuals who value their work can often combat the negative effects of abusive supervision to a certain extent because they are usually more invested in and take pride in their work, but eventually abusive supervision will wear down these employees as well. The longer this behavior is carried on, the more extreme these effects can become, as the subordinate experiences a cumulative loss of psychological resources (per COR theory) that makes them less resilient and more vulnerable to stressors (Carlson et al., 2012). Subordinates' willingness to confront their supervisor about an injustice will decrease as they believe their boss to be more abusive (Hoobler et al., 2006). The employee may also find that their life outside of work is being affected by this stressful work situation.

Abusive supervision can lead to more proximal employee outcomes such as low job satisfaction and higher turnover - both of which can be very costly to organizations and can directly affect their organizational culture. Employees might begin to show increased counterproductive work behaviors and decreased organizational citizenship behaviors (Martinko et al., 2013). The mere exposure to negative interpersonal conflicts at work has been linked to elevated levels of employee distress and becomes perpetually more severe because employees who report being distressed tend to interpret subsequent events more negatively (Mikkelsen \& Einarsen, 2002). Subordinates who experience abusive supervision tend to feel undervalued and view themselves as social outcasts in the workplace (Michel et al., 2015). Employees may seek to restore their sense of self-esteem following the experience of abusive supervision by lashing out at the perpetrator of this abuse and the organization that allowed this abuse to occur (Bowling 
\& Michel, 2011). That is, victims of abusive supervision and other forms of workplace mistreatment are more likely to become perpetrators of interpersonal and organizational deviance themselves (Hershcovis et al., 2010). As a result, mistreatment behaviors such as abusive supervision may propagate from one person to another. Abusive behavior among high-level managers can promote abusive behavior among the lower level managers who experienced the abuse (Mawritz, Mayer, Hoobler, Wayne, \& Marinova, 2012).

As mentioned above, abusive supervision can also have implications for the home environment of subordinates and their relationships outside of work. In other words, work interactions and experiences can spill over to non-work interactions and experiences. When subordinates feel abused by their supervisors, they may take out their frustration and strain on family members (Hoobler et al., 2006). This is a concept is known as family undermining, which suggests that negative workplace encounters serve as "emotional training grounds" for negative home encounters (Tedeschi et al., 1985, p. 30). Employees who are put down by their supervisors may feel the need to put down family members as a result (Hoobler et al. 2006). Subordinates may also use displaced aggression to redirect their desire to harm their supervisors onto a secondary target. That is, subordinates might engage in displaced aggression toward their family members when they experience abusive supervision. Because they cannot confront the direct source of their work-related stress, the supervisor, they turn to people with less power like their family members so as to exert some semblance of control.

There is evidence that the strain of one spouse affects the other. Husbands' job stressors have been found to be positively associated with distress in their wives (Rook, Dooley, \& Catalano, 1991). This displaced aggression or redirection of a subordinate's frustrations toward their family members can come in the form of increased arguing, negative mood states, and 
conflicting interactions (Hoobler et al., 2006). This suggests that workplace abuse may result in negative interpersonal relations in the home, which in turn can contribute to a negative, downward spiral of relationships in both spheres (Hoobler et al. 2006). If all employees in an organization target less powerful people towards whom they may displace their aggression, this can result in a vicious cycle of workplace aggression with the collateral damage affecting employees' families and home lives.

Consequences for coworkers. The negative effects of abusive supervision can also affect other employees who may just be innocent bystanders that are not involved in the situation in any way, thereby highlighting the broad reach of acts of abusive supervision. Vicariously experienced abusive supervision can also affect employees' perceptions of the workplace, which may then influence the behavioral tendencies of those employees (Mackey, Frieder, Perrewe, Gallagher, \& Brymer, 2014). Witnessing abusive supervision elicits different emotions from third parties, depending on their beliefs about the target of the abuse (Mitchell et al., 2015). It can motivate employees to engage in counterproductive behavior that may be harmful to coworkers (Harris, Harvey, Harris, \& Cast, 2013) and prosocial behavior intended to help the target of the abuse (Priesemuth, 2013). Traditionally, research suggests that witnessing abusive supervision would anger third-party employees and motivate them to harm the perpetrator because they believe that mistreating others is unfair (Folger, 1998, 2001); however, not all third-party employees believe it is unfair to mistreat specific coworkers and may experience contentment from the abuse (Mitchell et al., 2015). Third-party employees who experience anger may be motivated to harm the supervisor and support the target, while third-party employees who experience contentment may exclude the target (Mitchell et al., 2015). Employees can also 
become more abusive to other employees in reaction to abusive supervision, even if they are not direct targets of the abuse (Harris et al., 2013).

Consequences for organizations. Abusive supervision is also costly to the organization as a whole. Research has shown that abusive supervision is a widespread and costly organizational problem that results in annual organizational costs of approximately $\$ 23.8$ billion, as stated in the introduction, including increased healthcare costs, workplace withdrawal, and lost productivity (Tepper et al., 2006). A prominent reaction of those who are mistreated by their supervisors is workplace deviance. Workplace deviance is defined as voluntary acts that undermine the interests of an organization and its members (Robinson \& Bennett, 1995), and such acts can range from production and property deviance (e.g., taking long breaks, equipment theft, and/or sabotage) to interpersonal deviance and aggression (e.g., favoritism, gossip, and verbal abuse) (Michel et al., 2015). This form of retaliation to mistreatment can be perceived as appropriate if it is perpetuated by organizational norms (Michel et al., 2015).

As for the organizational consequences, workplace deviance has been shown to have an economic cost of about $\$ 4.2$ billion to organizations in lost productivity and legal fees. These estimates point to the urgency and need to address this organizational problem.

Consequences for supervisors. One perspective that has been neglected so far in this current research is the potential consequences faced by the abusive supervisor. Supervisors that choose to act aggressively or abusively toward their employees may experience supervisortargeted aggression as a consequence for their behavior (Inness et al., 2005). If abused subordinates do not feel they have the option to leave their job, they may decide to try and resolve the problem through their own aggression which can then be harmful to the supervisor (Inness et al., 2005). It is worth noting that there are some employees who may behave 
aggressively, even to a non-abusive supervisor (Inness et al., 2005). The minimal amount of research on this topic has focused on reactive aggression, and future research should focus on instrumental motives for aggression by subordinates in order to get a clearer picture of the negative effect of abusive supervision on the supervisor (Inness et al., 2005). Finally, future research should address the potential affective consequences experienced by perpetrators of abusive supervision. For example, research should investigate whether such perpetrators experience shame, guilt, or anxiety as a result of their enactment of such aggressive behaviors.

\section{Proposal for Preventive Measures}

In the following section, I use this foundation of knowledge on abusive supervision to provide suggestions on how organizations can respond to and prevent incidences of abusive supervision. To begin, eliminating all forms of abusive supervision from the workplaces should be the objective of the organization (Harvey et al., 2007). However, since this is not a feasible plan, organizations should use the resources they have to help manage the levels of abusive supervision in the workplace. Many of the aforementioned researchers have included a section at the end of their research study discussions that relates their research findings to practical implications for leaders, subordinates, senior management, and the organization as a whole (Kant, Skogstad, Torsheim, \& Einarsen, 2012). These practical implications are referred to throughout this section as a starting point for creating a set of preventive measures.

The framework for this proposal for preventive measures is adapted from a framework for preventive health management that has been applied to health psychology and preventive medicine. This framework can also be used in the context of occupational health and safety (Quick, 1999). In this framework, there are three levels of preventative intervention: primary, secondary, and tertiary (see Figure 3). Primary intervention is the preferred point of intervention 
that aims to identify then eliminate or mitigate health risks, secondary intervention is the next best alternative that aims to arrest diseases or disorders at the asymptomatic stage, and tertiary intervention is the last resort — when primary and secondary interventions have failed — that provides individuals with therapeutic relief (Quick, 1999).

\section{Primary Intervention \\ The preferred point of intervention that aims to identify then eliminate or mitigate health risks.}

\section{Secondary Intervention}

The next best alternative that aims to arrest diseases or disorders at the asymptomatic stage

\section{Tertiary Intervention}

The last resort, when primary and secondary interventions have failed, that provides individuals with therapeutic relief.

Figure 3. The three levels of preventive intervention (adapted from Quick, 1999).

These three prevention strategies are applicable to occupational health and safety, with primary prevention aiming to manage organizational demands and occupational health risks (Quick, 1999). Given what is known about the effects of abusive supervision on organizational and individual health, primary prevention strategies would be most effective. Secondary and tertiary intervention strategies should also be in place, in the event that primary prevention strategies prove unsuccessful or ineffective. Figure 4 illustrates these three prevention strategies in the organizational context. Primary prevention involves organizational demands and occupational health risks, secondary prevention involves low intensity, low cost individual and 
organizational problems, and tertiary prevention involves high intensity, high cost individual and organizational health problems (Quick, 1999).

\section{Primary Prevention}

Organizational demands and occupational health risks (i.e. spreading awareness about the risks associated with abusive supervisory behaviors).

\section{Secondary Prevention}

Low intensity, low cost individual and organizational health problems (i.e. resolving a situation involving an abusive supervisor).

\section{Tertiary Prevention}

High intensity, high cost individual and organizational health problems (i.e. dealing with turnover costs associated with unaddressed abusive supervisory behaviors).

Figure 4. Preventive health management in the organizational context (adapted from Quick, 1999)

Primary prevention strategies should focus on increasing organizational knowledge of abusive supervision, specifically its definition, antecedents, and consequences. All employees in an organization should have a basic understanding of behaviors associated with abusive supervision, including the behaviors exhibited by the supervisor and subordinate, in order to be able to identify these behaviors should they occur. Tepper's (2000) 15-item abusive supervision scale can be used to assess whether an employee is experiencing abusive supervision. The BussPerry Aggression Scale (Buss \& Perry, 1992) can be used to monitor levels of aggression in employees. Michel's (2014) 30-item Aggression Scale can also be used to assess levels of aggression, and is specifically targeted toward identifying specific biases such as hostile attribution bias. These resources are located in Appendix B and can be used by organizations and 
individual employees as a primary prevention tool. Another goal of the primary prevention strategy is to ensure that all employees have the necessary psychological resources - both personal and job-related - to do their jobs well and avoid burnout.

As a secondary prevention strategy, organizations should emphasize inhibiting supervisors' abusive behavior by informing supervisors about the adverse consequences of abusive supervision and by creating policies and procedures that serve to punish abusive behaviors $(\mathrm{Xu}$ et al., 2015). Tertiary prevention strategies - such as policies referring to disciplinary action for the abusive supervisors and legal measures protecting abused subordinates - should be set in place as a last resort. Because victims of abuse are more likely to keep silent than report their supervisors' dysfunctional behavior, it is critical that organizations set up safe channels for employees to report any abusive supervisory behavior, and also have protective policies in place in anticipation of supervisor retaliation (Xu et al., 2015).

It is also important for organizations to assess themselves in regards to organizational fairness. Employees assess organizational fairness on a number of dimensions. They make judgments about distributive justice (i.e., the perceived fairness of the outcomes they receive), procedural justice (i.e., the perceived fairness of the organization's formal procedures for dealing with employees), informational justice (i.e., the extent to which explanations for outcomes are perceived as reasonable and timely), and interactional justice (i.e., the extent to which employees perceive themselves to be treated with dignity in their interpersonal interactions, such as being treated with politeness and the absence of improper remarks or prejudicial statements) (Inness et al., 2005). It is important that organizations ensure that employees know that they are being treated fairly in relation to all of these dimensions, as perceptions of injustice have been shown to be antecedents of abusive supervision. 
The link between leaders' personal resource depletion and positive and negative forms of leadership emphasizes the need for organizational interventions and initiatives that support leaders (Byrne et al., 2014). Organizations are responsible for understanding and communicating the importance of leaders' well-being (Byrne et al., 2014). Given the link between resource depletion and abusive supervision, organizations should foster conditions that support resource acquisition, especially to employees who have depleted their resources (Hobfoll, 2001). These resources could include reducing work overload, offering training, and providing supplies for leaders, which are not only resources that help them perform well but also help buffer the negative effects of psychological resource depletion (Byrne et al., 2014).

By examining resource depletion as a precursor to abusive supervision, organizations can gain insight into what can be done to prevent or address this type of leadership (Byrne et al., 2014). Organizations can help employees regain their self-regulatory resources by encouraging them to take short breaks at work (Trougakos, Beal, Green, \& Weiss, 2008). Research has also shown that self-affirmation training can enable individuals to replenish their depleted resources (Schmeichel \& Vohs, 2009).

Hoobler and $\mathrm{Hu}$ (2013) also recommend leadership training programs, specifically those that include open discussions about the negative implications of abusive behavior, and roleplaying showing what behaviors are not only considered abusive by subordinates but also what alternative leadership styles are recommended for higher morale. Organizations should also strive to implement fair practices and policies that do not trigger supervisors' injustice perceptions and negative affect, which could prompt dysfunctional and abusive behaviors (Hoobler \& Hu, 2013). Companies need to ensure that employees' psychological contracts are realistic and in-line with the organization's exchange relationship with the employee because 
unrealistic expectations can cause interpersonal aggressive behavior (Hoobler et al., 2006). Expectations that employees hold about what constitutes a fair workplace could include recognition for specific accomplishments, notification of organizational changes that affect their jobs, and manager consideration of their individual needs for work-life flexibility (Hoobler et al., 2013). Given that a small body of literature has suggested an increased prevalence of abusive supervision in mechanistic, as opposed to organic, organizational structures, organizational leaders should consider the impact of their organization's structure and work climate on the levels of abusive supervision in the workplace (Tepper, 2007). Further, establishing policies, procedures, and practices to enhance the organization's mistreatment-reduction climate may reduce occurrences of mistreatment such as abusive supervision as well as enhance other desired outcomes such as job satisfaction and organizational commitment (Yang et al., 2014). Additional research would be helpful in determining whether there is an ideal organizational structure or climate that discourages and prevents abusive supervision (Tepper, 2007). Gaps like this in the current abusive supervision literature are discussed in the next section.

\section{Gaps in the Research}

Although an extensive amount of research has been conducted on the negative consequences of abusive supervision at both the individual and organizational level, there is still much to learn about the phenomenon. As reported above, multiple researchers have pointed out that the responsibility falls on the shoulders of the organization to identify and prevent abusive supervision. I was unable to identify any studies conducted that tested any potential prevention strategies at the organizational level. There has been some research done on coping strategies on the individual level, but only a handful of suggestions have been offered as coping strategies for organizations. Part of the reason this gap exists is because employees often become silent and do 
not come forward when they are being abused by their supervisors. This is mainly because they are dependent on their supervisors for desirable resources such as continued employment and advancement opportunities (Tepper, Moss, Lockhart, \& Carr, 2007). They tend to have some sort of avoidant or passive coping strategy that involves distancing themselves from the sources of the stress and attempting to avoid feedback from their supervisor (Tepper et al., 2007).

Research has demonstrated the broad range of negative consequences associated with abusive supervision, but very little research has focused on its antecedents. Of the scant evidence available, relational dynamics such as a contract breach, organizational injustice, and perceived leader-subordinate dissimilarities predict abusive supervision as do certain leader and subordinate characteristics (Hoobler et al., 2006; Tepper et al., 2006; Tepper, Moss, \& Duffy, 2011).

A majority of the data in early research on abusive supervision was from single sources, usually the subordinate, and almost all of the research designs were cross-sectional (Tepper, 2007). The majority of research has taken place within the United States (Tepper, 2007), meaning that there is still much to learn about how the nomological network of abusive supervision might differ across cultures (Martinko et al., 2013). Research has also suggested that organizational norms and organizational climate might promote or attenuate abusive tendencies in supervisors, but this is another aspect of abusive supervision that has received little attention (Tepper, 2007). The industry effects of abusive supervision also remain unstudied (Martinko et al., 2013).

These gaps in the current research represent areas in which future studies should be concentrated. Prior research has been driven by a considerable interest in the consequences of abusive supervision, which is an important aspect of abusive supervision research, but it should 
not be the only consideration. The literature on abusive supervision has shown evidence of various negative consequences, which should be enough to persuade organizations that this is a serious problem. Researchers can now turn to the more neglected segments of this literature such as understanding the experiences of the supervisor that correspond to the enactment of abusive behaviors toward subordinates - in order to shift the focus from understanding abusive supervision to preventing it.

\section{Implications for Future Research}

Research on abusive supervision has reached the point where researchers can now shift their focus to the gaps discussed above. There is an opportunity for future research to investigate the impact of cultural differences on abusive supervision antecedents, perceptions, and reactions, and this research will help establish the cross-cultural stability of abusive supervision scales (Martinko et al., 2013). Further, using longitudinal designs instead of cross-sectional study designs will allow researchers to rule out reverse or reciprocal causation in models of abusive supervision antecedents and outcomes (Martinko et al., 2013).

Researchers should also shift their focus from the consequences and outcomes of abusive supervision to the characteristics that might predispose supervisors toward abusive behaviors (Tepper, 2007). This is a more preventive approach toward abusive supervision research, compared to the traditional approach of focusing on the consequences and outcomes. While there is a small body of literature that suggests that organizational factors might promote abusive supervision, this is an area where additional research is needed (Martinko et al., 2013). Research on the industry effects of abusive supervision would also be beneficial because it could help identify segments of society where an understanding of abusive supervision is needed most (Martinko et al., 2013). 
Future research would also benefit from focusing on implementing programs in organizations that both encourage employees to report abusive supervision in the workplace and also on preventing abusive supervision from happening in the first place. There is a lot of information available regarding the practical implications of this research and how it can be applied to organizations, but it would be beneficial to start testing these theoretical implications in a real-time organizational setting. Research on creating a mistreatment-reduction climate via aggression-preventive supervisor behaviors (Yang \& Caughlin, 2016) and other existing programs that enhance positive organizational climate for reducing mistreatment (e.g., CREW; Leiter et al., 2011) can be used as a starting point for reducing abusive supervision in the workplace, as abusive supervision is a specific type of workplace mistreatment.

\section{Conclusion}

The central objective of this paper is to create a foundation of knowledge and understanding of abusive supervision, its antecedents, and its effects on an individual and organizational level. Organizations can then use this foundation to identify and prevent the occurrence of abusive supervision before it becomes a large-scale - and costly - organizational problem. The articles referenced throughout this paper have made important and critical contributions to the growing body of literature on abusive supervision. This research has provided a wealth of practical implications that organizations should utilize to maximize individual and organizational productivity by reducing and preventing abusive supervision. Abusive supervision can result in organizational costs of approximately $\$ 23.8$ billion (Tepper et al., 2006). The negative effects on each individual employee, whether they are the abuser or the abused, trickle down throughout the entire organization. It is in the hands of the organization to stop this negative spiral, preferably before it starts. This paper gives suggestions for preliminary 
steps toward implementing a training and development program focused on identifying and preventing abusive supervision, and organizations are encouraged to use these as a resource when creating and testing the effectiveness of such programs.

Mistreatment of any kind in an organization has tangible and intangible consequences and should not be tolerated. Abusive supervision is a clearly defined construct with concrete behaviors that can be identified by any member of an organization if they have been trained to recognize them. Moreover, more conflict-free workplaces mean less stressed workers and more conflict-free home lives (Hoobler et al., 2013). In closing, the goal of every organization should be to eliminate abusive supervision entirely. 


\section{References}

Andersson, L. M., \& Pearson, C. M. (1999). Tit for tat? The spiraling effect of incivility in the workplace. Academy of Management Review, 24(3), 452-471.

Aquino, K., Tripp, T. M., \& Bies, R. J. (2001). How employees respond to personal offense: the effects of blame attribution, victim status, and offender status on revenge and reconciliation in the workplace. Journal of Applied Psychology, 86(1), 52-59.

Aryee, S., Sun, L. Y., Chen, Z. X. G., \& Debrah, Y. A. (2008). Abusive supervision and contextual performance: The mediating role of emotional exhaustion and the moderating role of work unit structure. Management and Organization Review, 4, 393-411.

Ashforth, B. (1994). Petty tyranny in organizations. Human Relations, 47, 75-778.

Bamberger, P. A., \& Bacharach, S. B. (2006). Abusive supervision and subordinate problem drinking: Taking resistance, stress, and subordinate personality into account. Human Relations, 59, 723-752.

Barling, J. (1996). The prediction, experience, and consequences of work-place violence. In G.R. VandenBos \& E. Q. Bulatao (Eds.), Violence on the job: Identifying risks and developing solutions (pp. 29-49). Washington, DC: American Psychological Association.

Baumeister, R.F., Bratslavsky, E., Muraven, M., \& Tice, D.M. (1998). Ego depletion: Is the active self a limited resource? Journal of Personality and Social Psychology, 74, 12521265.

Bowling, N. A., \& Michel, J. S. (2011). Why do you treat me badly? The role of attributions regarding the cause of abuse in subordinates' responses to abusive supervision. Work \& Stress, 25(4), 309-320.

Brodsky, C.M. (1976). The Harassed Worker. MA. Toronto: Lexington Books, D.C. 
Bronfenbrenner, U., \& Morris, P. A. (1998). The ecology of developmental processes. In W. Damon (Series Ed.) \& R. M. Lerner (Vol. Ed.), Handbook of child psychology: Vol. 1. Theory (5th ed.). New York: Wiley.

Buss, A. H., \& Perry, M. P. (1992). The aggression questionnaire. Journal of Personality and Social Psychology, 63, 452-459.

Byrne, A., Dionisi, A. M., Barling, J., Akers, A., Robertson, J., Lys, R., Dupré, K. (2014). The depleted leader: The influence of leaders' diminished psychological resources on leadership behaviors. The Leadership Quarterly, 25(2), 344-357.

Carlson, D., Ferguson, M., Hunter, E., \& Whitten, D. (2012). Abusive supervision and workfamily conflict: The path through emotional labor and burnout. The Leadership Quarterly, 23(5), 849-859.

Chi, S.-C. S., \& Liang, S.-G. (2013). Corrigendum to "When do subordinates' emotionregulation strategies matter? Abusive supervision, subordinates' emotional exhaustion, and work withdrawal” [Lead. Quart. 28 (2013) 125-137]. The Leadership Quarterly, $24(4), 623$.

Chi, S.-C. S., \& Liang, S.-G. (2013). When do subordinates' emotion-regulation strategies matter? Abusive supervision, subordinates' emotional exhaustion, and work withdrawal. The Leadership Quarterly, 24(1), 125-137.

Cropanzano, R., \& Folger, R. (1989). Referent cognitions and task decision autonomy: Beyond equity theory. Journal of Applied Psychology, 74(2), 293-299.

DeWall, C. N., Baumeister, R. F., Stillman, T. F., \& Gailliot, M. T. (2007). Violence restrained: Effects of self-regulation and its depletion on aggression. Journal of Experimental Social Psychology, 43(1), 62-76. 
Diener, E., \& Fujita, F. (1995). Resources, personal strivings, and subjective well-being: A nomothetic and idiographic approach. Journal of Personality and Social Psychology, $68(5), 926-935$.

Duffy, M. K., Ganster, D. C., \& Pagon, M. (2002). Social undermining in the workplace. Academy of Management Journal, 45(2), 331-351.

Einarsen, S. (2000). Harassment and bullying at work: A review of the Scandinavian approach. Aggression and Violent Behavior, 5(4), 379-401.

Einarsen, S., Aasland, M. S., \& Skogstad, A. (2007). Destructive leadership behaviour: A definition and conceptual model. The Leadership Quarterly, 18(3), 207-216.

Einarsen, S., Hoel, H., \& Cooper, C. (Eds.). (2003). Bullying and emotional abuse in the workplace: International perspectives in research and practice. CRC Press: New York.

Finkel, E. J., \& Campbell, W. K. (2001). Self-control and accommodation in close relationships: an interdependence analysis. Journal of Personality and Social Psychology, 81(2), 263277.

Finkelstein, S., Hambrick, D. C., \& Cannella, A. (1996). Strategic leadership. West: St. Paul, Minn.

Folger, R. (1998). Fairness as moral virtue. In M. Schminke (Ed.), Managerial ethics: Moral management of people and processes (pp. 13-34). Mahwah, NJ: Erlbaum.

Folger, R. (2001). Fairness as deonance. In S. Gilliland, D. Steiner, \& D. Skarlicki (Eds.), Theoretical and cultural perspectives on organizational justice (pp. 3-33). Greenwich, CT: Information Age.

Folger, R., \& Baron, R. A. (1996). Violence and hostility at work: A model of reactions to perceived injustice. In G. R. VandenBos \& E. Bulatao (Eds.), Violence on the job: 
Identifying risks and developing solutions (pp. 51-85). Washington, DC: American Psychological Association.

Furnham, A., \& Taylor, J. (2004). The dark side of behavior at work. Understanding and avoiding employees leaving, thieving, and deceiving. New York, NY: Palgrave Macmillan.

Gemzøe Mikkelsen, E., \& Einarsen, S. (2002). Relationships between exposure to bullying at work and psychological and psychosomatic health complaints: The role of state negative affectivity and generalized self-efficacy. Scandinavian Journal of psychology, 43(5), $397-405$.

Glambek, M., Matthiesen, S. B., Hetland, J., \& Einarsen, S. (2014). Workplace bullying as an antecedent to job insecurity and intention to leave: a 6-month prospective study. Human Resource Management Journal, 24(3), 255-268.

Greenberg, J. (1993). Stealing in the name of justice: Informational and interpersonal moderators of theft reactions to underpayment inequity. Organizational Behavior and Human Decision Processes, 54, 81-103.

Hackman, J. R. (2002). Leading teams: Setting the stage for great performances. Boston, MA: Harvard Business Press.

Hampton, J. (1988). The retributive idea. In J. G. Murphy \& J. Hampton (Eds.), Forgiveness and Mercy (pp. 111-161). New York: Cambridge University Press.

Harris, K. J., Harvey, P., Harris, R. B., \& Cast, M. (2013). An investigation of abusive supervision, vicarious abusive supervision, and their joint impacts. Journal of Social Psychology, 153, 38-50. 
Harris, K. J., Kacmar, K. M., \& Zivnuska, S. (2007). An investigation of abusive supervision as a predictor of performance and the meaning of work as a moderator of the relationship. The Leadership Quarterly, 18(3), 252-263.

Harvey, P., Stoner, J., Hochwarter, W., \& Kacmar, C. (2007). Coping with abusive supervision: The neutralizing effects of ingratiation and positive affect on negative employee outcomes. The Leadership Quarterly, 18(3), 264-280.

Hedgcock, W. M., Vohs, K. D., \& Rao, A. R. (2012). Reducing self-control depletion effects through enhanced sensitivity to implementation: Evidence from fMRI and behavioral studies. Journal of Consumer Psychology, 22(4), 486-495.

Hershcovis, M. S. (2011). "Incivility, social undermining, bullying... oh my!”: A call to reconcile constructs within workplace aggression research. Journal of Organizational Behavior, 32(3), 499-519.

Hershcovis, M. S., \& Barling, J. (2010). Towards a multi-foci approach to workplace aggression: A meta-analytic review of outcomes from different perpetrators. Journal of Organizational Behavior, 31(1), 24-44.

Hinkin, T. R., \& Tracey, J. B. (2000). The cost of turnover. Cornell Hospitality Quarterly, 41(3), $14-21$.

Hobfoll, S. E. (1989). Conservation of resources: A new attempt at conceptualizing stress. American Psychologist, 44, 513-524.

Hobfoll, S. E. (2001). The influence of culture, community, and the nested-self in the stress process: Advancing conservation of resources theory. Applied Psychology: An International Review, 50, 337-421. 
Hoobler, J. M., \& Brass, D. J. (2006). Abusive supervision and family undermining as displaced aggression. Journal of Applied Psychology, 91(5), 1125-1133.

Hoobler, J. M., \& Hu, J. (2013). A model of injustice, abusive supervision, and negative affect. The Leadership Quarterly, 24(1), 256-269.

Hornstein, H.A. (1996) Brutal Bosses and their prey. New York, NY: Riverhead Books.

Inness, M., Barling, J., \& Turner, N. (2005). Understanding supervisor-targeted aggression: a within-person, between-jobs design. Journal of Applied Psychology, 90(4), 731-739.

Kahn-Greene, E. T., Lipizzi, E. L., Conrad, A. K., Kamimori, G. H., \& Killgore, W. D. S. (2006). Sleep deprivation adversely affects interpersonal responses to frustration. Personality and Individual Differences, 41, 1433-1443

Kant, L., Skogstad, A., Torsheim, T., \& Einarsen, S. (2013). Beware the angry leader: Trait anger and trait anxiety as predictors of petty tyranny. The Leadership Quarterly, 24(1), $106-124$.

Kelloway, E. K., Mullen, J., \& Francis, L. (2006). Divergent effects of transformational and passive leadership on employee safety. Journal of Occupational Health Psychology, 11(1), 76-86.

Kelloway, E. K., Turner, N., Barling, J., \& Loughlin, C. A. (2012). Transformational leadership, transactional leadership, and employee psychological well-being: The mediating role of trust. Work and Stress, 26, 39-55.

Kiewitz, C., Restubog, S. L. D., Zagenczyk, T. J., Scott, K. D., Garcia, P. R. J. M., \& Tang, R. L. (2012) Sins of the parents: Self-control as a buffer between supervisors' previous experience of family undermining and subordinates' perceptions of abusive supervision. The Leadership Quarterly, 23(5), 869-882. 
Kile, S.M. (1990) Helsefarleg Leierskap (health endangering leadership). Bergen, Norway:

Leiter, M. P., Laschinger, H. K. S., Day, A., \& Oore, D. G. (2011). The impact of civility interventions on employee social behavior, distress, and attitudes. Journal of Applied Psychology, 96(6), 1258-1274.

Lipman-Blumen, J. (2005). The allure of toxic leaders. Why we follow destructive bosses and corrupt politicians - and how we can survive them. Oxford: Oxford University Press.

Lombardo, M. M., \& McCall, M. W. J. (1984). Coping with an intolerable boss. Greensboro, NC: Center for Creative Leadership.

Mackey, J. D., Frieder, R. E., Perrewé, P. L., Gallagher, V. C., \& Brymer, R. A. (2014). Empowered Employees as Social Deviants: The role of abusive supervision. Journal of Business and Psychology, 30(1), 149-162.

Martinko, M. J., Harvey, P., Brees, J. R., \& Mackey, J. (2013). A review of abusive supervision research. Journal of Organizational Behavior, 34(S1), S120-S137.

Mawritz, M. B., Mayer, D. M., Hoobler, J. M., Wayne, S. J., \& Marinova, S. V. (2012). A trickle-down model of abusive supervision. Personnel Psychology, 65, 325-257.

Michel, J. S., Newness, K., \& Duniewicz, K. (2015). How abusive Supervision affects workplace deviance: A moderated-mediation examination of aggressiveness and work-related negative affect. Journal of Business and Psychology, 31(1), 1-22.

Michel, J. S., Pace, V. L., Edun, A., Sawhney, E., \& Thomas, J. (2014). Development and validation of an explicit aggressive beliefs and attitudes scale. Journal of Personality Assessment, 96(3), 327-338. 
Mitchell, M. S., \& Ambrose, M. L. (2007). Abusive supervision and workplace deviance and the moderating effects of negative reciprocity beliefs. Journal of Applied Psychology, 92(4), 1159-1168.

Mitchell, M. S., Vogel, R. M., \& Folger, R. (2015). Third parties' reactions to the abusive supervision of coworkers. Journal of Applied Psychology, 100(4), 1040-1055.

Namie, G., \& Namie, R. (2000). The bully at work. What you can do to stop the hurt and reclaim the dignity on the job. Naperville, IL: Sourcebooks, Inc.

Parry, K. W. (2011). Leadership and organization theory. In A. Bryman, D. Collinson, K. Grint, B. Jackson, \& M. Uhl-Bien (Eds.), Sage handbook of leadership (pp. 53-70). London, UK: Sage Publications.

Priesemuth, M. (2013). Stand up and speak out: Employees' prosocial reactions to observed abusive supervision. Business \& Society, 52, 649-665.

Quick, J. C. (1999). Occupational health psychology: Historical roots and future directions. Health Psychology, 18(1), 82-88.

Robinson, S. L., \& Bennett, R. J. (1995). A typology of deviant workplace behaviors: A multidimensional scaling study. Academy of Management Journal, 38, 555-572.

Robinson, S. L., \& Rousseau, D. M. (1994). Violating the psychological contract: Not the exception but the norm. Journal of Organizational Behavior, 15(3), 245-259.

Romano, C. (1994). Workplace violence takes a deadly turn. Management Review, 83, 5.

Rook, K., Dooley, D., \& Catalano, R. (1991). Stress transmission: The effect of husbands' job stressors on the emotional health of their wives. Journal of Marriage and the Family, 53, $165-177$. 
Rousseau, D. M. (1995). Psychological contracts in organizations: Understanding written and unwritten agreements. Thousand Oaks, CA: Sage.

Schat, A. C. H., Frone, M., \& Kelloway, E. K. (2006). The prevalence of workplace aggression in the U.S. workforce: Findings from a national study. In E. K. Kelloway, J. Barling, \& J. J. Hurrell Jr. (Eds.), Handbook of workplace violence (pp. 579-606). Thousand Oaks, CA: Sage.

Schmeichel, B. J., \& Vohs, K. (2009). Self-affirmation and self-control: affirming core values counteracts ego depletion. Journal of Personality and Social Psychology, 96(4), 770-782.

Shackleton, V. (1995). Leaders who derail. In V. Shackleton (Ed.), Business Leadership. London, UK: Thomson.

Spector, P. E., \& Jex, S. M. (1998). Development of four self-report measures of job stressors and strain: interpersonal conflict at work scale, organizational constraints scale, quantitative workload inventory, and physical symptoms inventory. Journal of occupational health psychology, 3(4), 356-367.

Stucke, T. S., \& Baumeister, R. F. (2006). Ego depletion and aggressive behavior: Is the inhibition of aggression a limited resource? European Journal of Social Psychology, $36(1), 1-13$.

Tedeschi, J. T., \& Norman, N. (1985). Social power, self-presentation, and the self. The Self and Social Life, 293-322.

Tepper, B. J. (2000). Consequences of abusive supervision. Academy of Management Journal, 43(2), 178-190.

Tepper, B. J. (2007). Abusive supervision in work organizations: Review, synthesis, and research agenda. Journal of Management, 33(3), 261-289. 
Tepper, B. J., Duffy, M. K., Henle, C. A., \& Lambert, L. S. (2006). Procedural injustice, victim precipitation, and abusive supervision. Personnel Psychology, 59(1), 101-123.

Tepper, B. J., Duffy, M. K., Hoobler, J., \& Ensley, M. D. (2004). Moderators of the relationships between coworkers' organizational citizenship behavior and fellow employees' attitudes. Journal of Applied Psychology, 89(3), 455-465.

Tepper, B. J., Moss, S. E., \& Duffy, M. K. (2011). Predictors of abusive supervision: Supervisor perceptions of deep-level dissimilarity, relationship conflict, and subordinate performance. Academy of Management Journal, 54(2), 279-294.

Tepper, B. J., Moss, S. E., Lockhart, D. E., \& Carr, J. C. (2007). Abusive supervision, upward maintenance communication, and subordinates' psychological distress. Academy of Management Journal, 50(5), 1169-1180.

Trougakos, J. P., Beal, D. J., Green, S. G., \& Weiss, H. M. (2008). Making the break count: An episodic examination of recovery activities, emotional experiences, and positive affective displays. Academy of Management Journal, 51(1), 131-146.

UNISON (1997). UNISON's members' experience of bullying at work. London, UK: UNISON. Universitetet i Bergen.

Vigoda-Gadot, E. (2007). Redrawing the boundaries of OCB? An empirical examination of compulsory extra-role behavior in the workplace. Journal of Business and Psychology, 21(3), 377-405.

von Hippel, W., \& Gonsalkorale, K. (2005). “That is bloody revolting!”: Inhibitory control of thoughts better left unsaid. Psychological Science, 16(7), 497-500. 
Xiaqi, D., Kun, T., Chongsen, Y., \& Sufang, G. (2012). Abusive supervision and LMX: Leaders' emotional intelligence as antecedent variable and trust as consequence variable. Chinese Management Studies, 6(2), 257-270.

Xu, A. J., Loi, R., \& Lam, L. W. (2015). The bad boss takes it all: How abusive supervision and leader-member exchange interact to influence employee silence. The Leadership Quarterly, 26(5), 763-774.

Yam, K. C., Fehr, R., Keng-Highberger, F. T., Klotz, A. C., \& Reynolds, S. J. (2015). Out of control: A self-control perspective on the link between surface acting and abusive supervision. Journal of Applied Psychology.

Yang, L.-Q., \& Caughlin, D. E. (2016). Aggression-preventive supervisor behavior: Implications for workplace climate and employee outcomes. Journal of Occupational Health Psychology.

Yang, L.-Q., Caughlin, D. E., Gazica, M. W., Truxillo, D. M., \& Spector, P. E. (2014). Workplace mistreatment climate and potential employee and organizational outcomes: A meta-analytic review from the target's perspective. Journal of Occupational Health Psychology, 19(3), 315.

Yukl, G. (2002). Leadership in organizations. New Jersey: Prentice Hall.

Zhang, Y., \& Bednall, T. C. (2015). Antecedents of abusive supervision: A meta-analytic review. Journal of Business Ethics. 


\section{Appendices}

\section{Appendix A: Key Terms}

The key terms are listed in the table(s) below:

Table 1. Types of Leadership

\begin{tabular}{|c|c|}
\hline Types of Leadership & Definition \\
\hline Destructive Leadership & $\begin{array}{l}\text { "The systematic and repeated behavior by a } \\
\text { leader, supervisor, or manager, that violates the } \\
\text { legitimate interest of the organization by } \\
\text { undermining and/or sabotaging the } \\
\text { organization's goals, tasks, resources, and } \\
\text { effectiveness and/or the motivation, well-being } \\
\text { or job satisfaction of subordinates (Einarsen et } \\
\text { al. 2007, p. 208)." }\end{array}$ \\
\hline Abusive Supervision & $\begin{array}{l}\text { "The sustained display of hostile verbal and } \\
\text { nonverbal behaviors, excluding physical } \\
\text { contact (Tepper, 2000, p. 178)." }\end{array}$ \\
\hline Workplace Bullying & $\begin{array}{l}\text { "Instances where an employee is repeatedly } \\
\text { and over a period of time exposed to negative } \\
\text { acts (i.e. constant abuse, offensive remarks or } \\
\text { teasing, ridicule, or social exclusion) from co- } \\
\text { workers, supervisors, or subordinates } \\
\text { (Einarsen, 2000)." }\end{array}$ \\
\hline Social Undermining & $\begin{array}{l}\text { "Behavior intended to hinder, over time, the } \\
\text { ability to establish and maintain positive } \\
\text { interpersonal relationships, work-related } \\
\text { success, and favorable reputation (Duffy, } \\
\text { Ganster, \& Pagon et al., 2002)." }\end{array}$ \\
\hline Incivility & $\begin{array}{l}\text { "Low intensity deviant acts, such as rude and } \\
\text { discourteous verbal and nonverbal behaviors } \\
\text { enacted towards another organizational } \\
\text { member with ambiguous intent to harm } \\
\text { (Andersson \& Pearson et al., 1999)." }\end{array}$ \\
\hline Interpersonal Conflict & $\begin{array}{l}\text { "An organizational stressor involving } \\
\text { disagreements between employees (Spector \& } \\
\text { Jex, 1998)." }\end{array}$ \\
\hline
\end{tabular}


Table 2. Types of leaders

\begin{tabular}{|l|l|}
\hline Types of Leaders & Definition \\
\hline Abusive Leader & $\begin{array}{l}\text { "One whose primary objective is the control of } \\
\text { others, and such control is achieved through } \\
\text { methods that create fear and intimidation } \\
\text { (Hornstein, 1996.)" }\end{array}$ \\
\hline Petty Tyrant & $\begin{array}{l}\text { "Someone who uses their power and authority } \\
\text { oppressively, capriciously, and perhaps } \\
\text { vindictively (Ashforth, 1994, p. 126)." }\end{array}$ \\
\hline Health Endangering Leader & $\begin{array}{l}\text { "Someone who behaves in such a manner } \\
\text { towards subordinates that subordinates develop } \\
\text { poor health, and attribute these health problems } \\
\text { to the leader's behaviors (Kile, 1990, p. 26)." }\end{array}$ \\
\hline Toxic Leader & $\begin{array}{l}\text { "Leaders who act without integrity by } \\
\text { dissembling and engaging in various other } \\
\text { dishonorable behaviors, including behaviors } \\
\text { such as corruption, hypocrisy, sabotage and } \\
\text { manipulation, as well as other assorted } \\
\text { unethical, illegal and criminal acts (Lipman- } \\
\text { Bluman, 2005, p. 18)." }\end{array}$ \\
\hline
\end{tabular}




\section{Appendix B: Abusive Supervision Measurement Scales}

Abusive Supervision 15-Item Scale (Tepper et al., 2000)

The items were prefaced with the statement, "My boss..." Respondents used a five-point response scale shown here:

1 - I cannot remember him/her ever using this behavior with me

$2-\mathrm{He} / \mathrm{she}$ very seldom uses this behavior with me

$3-\mathrm{He} / \mathrm{she}$ occasionally uses this behavior with me

$4-\mathrm{He} / \mathrm{she}$ uses this behavior moderately often with me

$5-\mathrm{He} / \mathrm{she}$ uses this behavior very often with me

The items were:

1. Ridicules me

2. Tells me my thoughts or feelings are stupid

3. Gives me the silent treatment

4. Puts me down in front of others

5. Invades my privacy

6. Reminds me of my past mistakes and failures

7. Doesn't give me credit for jobs requiring a lot of effort

8. Blames me to save himself/herself embarrassment

9. Breaks promises he/she makes

10. Expresses anger at me when he/she is mad for another reason

11. Makes negative comments about me to others

12. Is rude to me

13. Does not allow me to interact with my coworkers

14. Tells me I'm incompetent

15. Lies to me

Buss-Perry Aggression Scale (Buss \& Perry, 2006)

Please rate each of the following items in terms of how characteristic they are of you. Use the following scale for answering these items:

$$
\begin{array}{lllllll}
1 & 2 & 3 & 4 & 5 & 6 & 7
\end{array}
$$

Where 1 is extremely uncharacteristic of me and 7 is extremely characteristic of me.

1) Once in a while I can't control the urge to strike another person. 
2) Given enough provocation, I may hit another person.

3) If somebody hits me, I hit back.

4) I get into fights a little more than the average person.

5) If I have to resort to violence to protect my rights, I will.

6) There are people who pushed me so far that we came to blows.

7) I can think of no good reason for ever hitting a person.

8) I have threatened people I know.

9) I have become so mad that I have broken things.

10) I tell my friends openly when I disagree with them.

11) I often find myself disagreeing with people.

12) When people annoy me, I may tell them what I think of them.

13) I can't help getting into arguments when people disagree with me.

14) My friends say that I'm somewhat argumentative.

15) I flare up quickly but get over it quickly.

16) When frustrated, I let my irritation show.

17) I sometimes feel like a powder keg ready to explode.

18) I am an even-tempered person.

19) Some of my friends think I'm a hothead.

20) Sometimes I fly off the handle for no good reason.

21) I have trouble controlling my temper.

22) I am sometimes eaten up with jealousy.

23) At times I feel I have gotten a raw deal out of life.

24) Other people always seem to get the breaks.

25) I wonder why sometimes I feel so bitter about things.

26) I know that "friends" talk about me behind my back. 
27) I am suspicious of overly friendly strangers.

28) I sometimes feel that people are laughing at me behind me back.

29) When people are especially nice, I wonder what they want.

30-Item Aggression Scale (Michel et al. 2014)

Victimization by powerful other bias items:

1. The wealthy capitalize on those who are less fortunate

2. The rich get richer by taking advantage of the poor

3. I believe that large corporations exploit their employees

4. Big companies intentionally rip off customers

5. Those in power stay in power by keeping others down

Derogation of target bias items:

6. Some people are simply horrible human beings

7. Some people are just bad people

8. Some people are completely immoral

9. There is not good in everyone

10. In general, people are either good or evil

Retribution bias items:

11. Getting back at others makes me feel better

12. If someone disrespects me, I feel the need to get even

13. People have the right to get revenge

14. Revenge is sweet

15. If I am betrayed then I have the right to retaliate

Hostile attribution bias items:

16. People gain others' trust to betray them

17. Friendliness is often a disguise for hostile interventions

18. People are motivated by a desire to harm others

19. People make friends in order to use them to get ahead in life

20. People give bad advice for personal gain

Potency bias items:

21. History is made through triumphs of the strong over the weak

22. Life presents challenges that separate the weak from the strong 
23. I want to be stronger than others

24 . Only the strong survive

25. It's important to establish who's boss

Social discounting bias items:

26. Common sense overrides the need for rules

27. I only follow rules that I find important

28. People follow too many unnecessary rules

29. Laws are meant to be broken

30. Any social rule that gets in the way of personal expression is a bad rule Note: Items should be assessed in a random order. 